after two to three days to an equilibrium level at $1 \%$ or less of the initial levels.

Our earlier studies (Lowbury et al., 1964b) showed that the low counts of skin bacteria reached after six successive treatments with a hexachlorophane detergent cream could be further reduced by disinfection of the same area with alcoholic chlorhexidine rubbed on with gauze ("two-phase" disinfection); this method could be useful in the disinfection of operation sites before elective operations in high-risk patients. These findings were confirmed in the present study, which also showed that two-phase disinfection could be obtained with Hibiscrub as the first-phase detergent preparation. When, however, the hands were washed with Hibiscrub immediately after the ninth of a series of hand washes with the same agent the secondphase treatment failed to cause any further reduction of skin bacteria. This finding parallels that obtained in an earlier study, when hands which had shown a large reduction in bacteria on two-minutes' disinfection with ethyl alcohol failed to show a further reduction on receiving a similar alcohol disinfection immediately afterwards (Lowbury and Lilly, 1960). In some of the experiments few bacteria were found on sampling the skin after the first-phase treatment so that the effect of the second phase could not be shown. The hypothesis that "twophase" disinfection of the skin depends for its effect on the distinct action of two different forms of disinfection was, however, supported by some of these experiments, in which there were differences in the chemistry of the disinfectant used, in the nature of the solvent, and in the mode of application. It is possible that alcohol used in the second phase of disinfection was active against bacteria persisting on the skin through the first phase because they were relatively resistant to chlorhexidine or hexachlorophane.

The other methods which seemed potentially useful for skin disinfection of the operation site of highly susceptible patients gave a somewhat disappointing result. Application for thirty minutes of povidone iodine compresses caused a reduction in the resident flora which was only marginally better than that obtained in a standard two minutes' disinfection with alcoholic iodine or chlorhexidine, and similar treatment with compresses of $0.5 \%$ chlorhexidine gave less satisfactory results. Compresses of povidone iodine provide the most effective method of eliminating bacterial spores on the skin (Lowbury et al., 1964), and when this procedure has been deliberately adopted to reduce hazards of gas gangrene-for example, before amputation of a leg in a patient with arterial insufficiency-the reduction in numbers of vegetative organisms is about the same as that which would be obtained by a standard skin disinfection of the operation site.

A comparison between repeated hand washing with $0.3 \%$ chlorocresol liquid soap and similar treatment with a $3 \%$ hexachlorophane detergent cream showed a larger and more consistent disinfectant action from the hexachlorophane preparation. A large cumulative reduction of skin bacteria was, however, usually caused by the use of chlorocresol soap. It is clearly a much more effective agent for cleaning the skin than ordinary soap, and probably more effective than hexachlorophane bar soap (Lowbury and Lilly, 1960).

These studies have shown that a $4 \%$ chlorhexidine detergent solution is a potentially outstanding addition to the small list of detergent-disinfectant preparations for the hands of surgeons and nurses, with a greater immediate effect than that obtained with the hexachlorophane or even the iodophor preparations. Like Ster-Zac liquid soap and unlike the $0.75 \%$ chlorhexidine detergent preparation previously studied, the $4 \%$ chlorhexidine preparation showed a residual action against bacteria, both Staph. aureus and $E$. coli, deposited on the skin after washing, rinsing, and drying the hands. These properties make Hibiscrub a potentially useful alternative to hexaclorophane detergent preparations for the protection of neonates against staphylococcal infection. Such alternatives are clearly required in the light of possible toxic absorption of hexachlorophane in some infants (Curley et al., 1971), but there appears to be none of proved effectiveness. Hibiscrub, if found safe and effective in infants, would probably have the additional advantage of giving no selective encouragement to Gram-negative infections-a side effect attributed to hexachlorophane (Forfar et al., 1968).

We are grateful to Dr. J. P. Bull for advice and to Mr. M. D. Wilkin for help with statistical assessments; to I.C.I. (Pharmaceuticals) Ltd. for supplies of Hibiscrub and Disadine; to Messrs. Hough-Hoseason for supplies of $0.3 \%$ chlorocresol liquid soap (Ozac), and of Dermofax; and to members of the staff of this unit for their collaboration in tests of skin disinfection.

\section{References}

Collins, B. J., and Deverill, C. E. A. (1971). Pharmaceutical fournal, 206, 369.

Curley, A., Hawk, R. E., Kimbrough, R. D., Nathenson, G., and Finberg, L. (1971). Lancet, 2, 296.

Drewett, S. E., Payne, D. J. H., Tuke, W., and Verdon, P. E. (1972). Lancet, 1, 1172 .

Forfar, J. O., Gould, J. C., and MacCabe, A. F. (1968). Lancet, 2, 177.

Lilly, H. A., and Lowbury, E. J. L. (1971). British Medical fournal, 3, 674.

Lowbury, E. J. L., and Lilly, H. A. (1960). British Medical fournal, $1,1445$.

Lowbury, E. J. L., Lilly, H. A., and Bull, J. P. (1960). British Medical fournal, 2,1039 .

Lowbury, E. J. L., Lilly, H. A., and Bull, J. P. (1963). British Medical Fournal, 1,1251 .

Lowbury, E. J. L., Lilly, H. A., and Bull, J. P. (1964a). British Medical fournal, 2, 230 .

Lowbury, E. J. L., Lilly, H. A., and Bull, J. P. (1964b). British Medical fournal, 2,531 .

Story, P. (1952). British Medical fournal, 2, 1128.
Department of Surgery, University of Khartoum, Sudan

M. A. HASSAN, M.S., F.R.C.S., Senior Lecturer

Radiation and Isotope Centre, Khartoum

E. A. RAHMAN, D.M.R.T., Director

I. A. RAHMAN, B.SC., Physicist incidence of nearly $30 \%$ in $\mathbf{5 4 2}$ patients reported from British hospitals using the same diagnostic technique. The reason for the difference is obscure and needs further investigation.

\section{Introduction}

The incidence of postoperative deep vein thrombosis in patients aged over 40 in British hospitals is from $25-30 \%$. Its incidence in the Sudan and, indeed, throughout Africa is generally believed to be lower than in Western society, but this has not, to our knowledge, been substantiated by proper clinical studies. 
This paper reports the results of a study by means of the ${ }^{128} \mathrm{I}$ fibrinogen test of the incidence of postoperative deep vein thrombosis in 100 Sudanese patients.

\section{Patients and Methods}

The study was carried out in Khartoum Civil Hospital on 91 male and 9 female surgical patients aged 40 years or over. So far as was possible the patients included were those undergoing operations said to be associated with a high incidence of thrombosis - that was, those undergoing prostatectomy (transvesical or retropubic but not transurethral) or major abdominal operations. Their age and sex distribution are given in table I and the types of operation in table II.

TABLB I-Age, Sex, and Incidence of Postoperative Deep Vein Thrombosis in 100 Sudaneso Patients

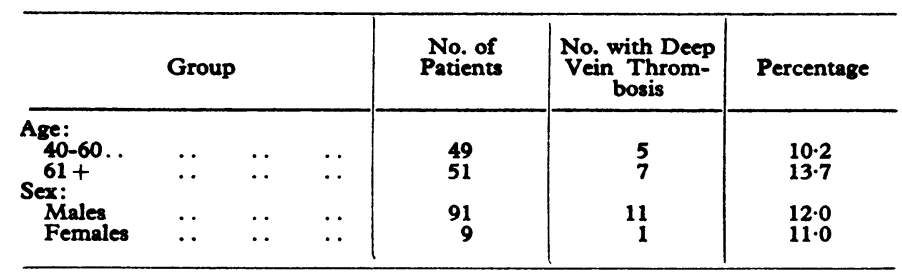

TABLE II-Incidence of Postoperative Deep Vein Thrombosis and Type of Operation

\begin{tabular}{|c|c|c|c|c|c|}
\hline \multicolumn{4}{|c|}{ Operation } & \multirow{2}{*}{$\begin{array}{r}\begin{array}{r}\text { No. of } \\
\text { Cases }\end{array} \\
57 \\
15 \\
8 \\
5 \\
5 \\
3 \\
5 \\
1 \\
1\end{array}$} & \multirow{2}{*}{$\begin{array}{c}\begin{array}{c}\text { Incidence of } \\
\text { Deep Vein } \\
\text { Thrombosis }\end{array} \\
4 \\
3 \\
1 \\
1 \\
1 \\
\frac{1}{1}\end{array}$} \\
\hline $\begin{array}{l}\text { Prostatectomy (52 tra } \\
\text { Vagotomy and draina } \\
\text { Cholecystectomy } \\
\text { Operations on the uri } \\
\text { Hip operation .. } \\
\text { Splenectomy .. } \\
\text { Herniorrhaphy } \\
\text { Nephrectomy ... } \\
\text { Haemorrhoidectomy }\end{array}$ & 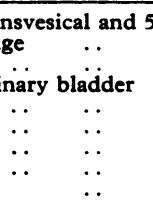 & \begin{tabular}{ll}
\multicolumn{3}{c}{ retropubic) } \\
$\ldots$ & $\ldots$ \\
$\ldots$ & $\ldots$ \\
$\ldots$ & $\ldots$ \\
$\ldots$ & $\ldots$ \\
$\ldots$ & $\ldots$ \\
$\ldots$ & $\ldots$ \\
$\ldots$ &.
\end{tabular} & $\begin{array}{l}\ldots \\
\because \\
\cdots \\
\therefore \\
\therefore \\
\therefore\end{array}$ & & \\
\hline Total & & & & 100 & 12 \\
\hline
\end{tabular}

The method used for the ${ }^{125}$ I-fibrinogen test was that of Negus et al. (1968), except that the measurement of radioactivity over the heart and legs was made by the portable Pitman 235 isotope localization monitor (Kakkar et al., 1970). The iodinated human fibrinogen was supplied by the Radiochemical Centre, Amersham, England.

The patients were examined the day before operation, particular attention being given to the legs, and were prescribed potassium iodide $150 \mathrm{mg} / 24 \mathrm{hr}$ in three divided doses orally for three weeks to block the thyroid gland. About three hours postoperatively $100 \mu \mathrm{Ci}$ of ${ }^{125} \mathrm{I}$ in $1.0 \mathrm{mg}$ fibrinogen was injected intravenously. Scanning of the heart and of the legs were started on the day of operation and continued daily for at least seven and in most cases 10 days. It was continued beyond 10 days when there was evidence of thrombosis. Thrombus formation was diagnosed when there was a persisting and increasing difference of $20 \%$ or more in the mean percentage uptake between adjacent points in the same limb or an equivalent point on the opposite limb (Pai and Negus, 1971). Clinical evidence of deep vein thrombosis in the legs was looked for daily, but the diagnosis was made only on the results of the ${ }^{125}$ I-fibrinogen test.

\section{Results}

The incidence of deep vein thrombosis related to age and sex is shown in table I and the incidence related to type of operation in table II.

Of the 12 patients who developed deep vein thrombosis, the thrombus was in the calf veins in 11 (bilaterally in one case) and in the superficial femoral vein in one. In none was there any evidence of proximal spread of the thrombosis. In only three of the patients was there clinical evidence to suggest deep vein thrombosis, and this evidence always presented after the thrombus had been detected by radioisotope scanning. In five patients the thrombosis was detected on the third postoperative day, in three on the fourth postoperative day, and in the remaining four between the fifth and seventh postoperative days. In one patient radioisotope study ruled out thrombosis despite suggestive clinical evidence (calf tenderness and minimal oedema of the ankle).

\section{Discussion}

The striking finding in this study is the relatively low incidence of postoperative deep vein thrombosis compared with that reported in other published series (table III). The incidence of $12 \%$ in our 100 patients is significantly different from that of $28 \%$ in a total of 542 patients in three British hospitals. Clearly the relatively low incidence in our series is not owing to a shortage of "high risk" cases nor to differences in age. The incidence in the 51 of our patients who were aged 61 or over was $13.7 \%$ still much lower than that reported in the literature.

TABLE III-Incidence of Postoperative Deep Vein Thrombosis in Sudanese Patients compared with reported Incidence in London Hospitals

\begin{tabular}{|c|c|c|}
\hline Series & $\begin{array}{l}\text { No. of } \\
\text { Patients }\end{array}$ & $\begin{array}{l}\text { Percentage with } \\
\text { Deep Vein } \\
\text { Thrombosis }\end{array}$ \\
\hline 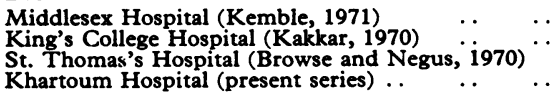 & $\begin{array}{r}280 \\
215 \\
47 \\
100\end{array}$ & $\begin{array}{l}28 \\
29 \\
28 \\
12\end{array}$ \\
\hline
\end{tabular}

The difference between $12 \%$ in 100 Sudanese patients and $28 \%$ in 542 patients in The difference between $12 \%$ in 100 Sudanese patients
London hospitals is statistically significant $(P<0.001)$.

The explanation of this low incidence of postoperative thrombosis in our patients is a matter for speculation. The predisposing causes of deep vein thrombosis are probably the postoperative hypercoagulable state, which occurs irrespective of whether deep vein thrombosis is present or not, and slowing of venous blood flow and stasis of blood during operation. There is indirect clinical evidence to support both these factors. Kakkar et al. (1971), Williams (1971), and Gordon-Smith et al. (1972) have significantly reduced the incidence of postoperative deep vein thrombosis by prophylactic subcutaneous injections of small doses of heparin, while other workers have taken steps during the operative procedure to combat venous stasis and increase venous flow (Browse and Negus, 1970; Sabri et al., 1971; Hills et al., 1972). Venous thrombosis probably occurs during the operation, and by giving the radioisotope after the operation we may have failed to detect thrombi already formed during the operation. Nevertheless, the radioisotope was also given postoperatively in most of the studies with which we have compared our results.

Some workers (Osman, 1969; Cleave, 1972; Burkitt, 1972) postulate that differences in disease pattern (including deep vein thrombosis) in different societies can be explained by differences in diet, the fibre-depleted diet characteristic of Western people resulting in faecal arrest and straining at stool and increases in venous pressure. This hypothesis may be true but at present it lacks proper scientific proof.

A possible explanation for the relatively low incidence of postoperative deep vein thrombosis in our patients may be that some of them had an abnormality in the coagulation mechanism. Lee et al. (1964) showed that East Africans (who are somewhat similar to our patients) had significantly lower levels of plasma fibrinogen and prothrombin concentrations and shorter euglobulin and clot lysis times than age- and sex-matched New 
Yorkers. Bradlow et al. (1962) showed that some of the coagulation factors were lower and that fibrinolysis was accelerated in South African Bantus compared with white controls. Preoperative and postoperative coagulation studies in our patients may help to explain the relatively low incidence of postoperative deep vein thrombosis among them.

We acknowledge with thanks the financial support given to this study by the International Atomic Energy Agency, Vienna. We also thank our surgical colleagues in Khartoum Civil Hospital who allowed us to study their patients.

\section{References}

Bradlow, B. A., Antonis, A., and Bearson, I. S. (1962). African fournal of Medical Science, 27, 15.
Browse, N. L., and Negus, D. (1970). British Medical fournal, 3, 615.

Burkitt, D. P. (1972). British Medical fournal, 3, 556.

Cleave, T. L. (1972). British Medical fournal, 1, 629.

Gordon-Smith, I. C., Grundy, D. J., Le Quesne, L. P., Newcombe, J. F., and Bramble, F.J. (1972). Lancet, 1, 1133 .

Hills, N. H., Pflug, J. J., Jeyasingh, K., Boardman, L., and Calnan, J. S. (1972). British Medical fournal, 1, 131.

Kakkar, V. V., Nicolaides, A. N., Renney, J. T. G., Friend, J. R., and Clarke, M. B. (1970). Lancet, 1, 540 .

Kakkar, V. V., Field, E. S., Nicolaides, A. N., Flute, P. T., Wessler, S., and Yin, E. T. (1971). Lancet, 2, 669 .

Kemble, J. V. H. (1971). British fournal of Hospital Medicine, 6, 721.

Lee, K. T., Kim, D. N.; Shaper, A. G., and Thomas, W. A. (1964). Experimental Mollecular Pathology, 3, 500 .

Negus, D., Pinto, D. J., Le Quesne, L. P., Brown, N., and Chapman, M. (1968). British fournal of Surgery, 55, 835.

Osman, A. A. (1969). Personal Communication.

Pabri, S., Roberts, V. C., and Cotton, L. T. (1971). British Medical fournal, 3,82 .

Williams. H, T. (1971). Lancet, 2, 950.

\title{
Deep Vein Thrombosis in a Queensland Hospital*
}

\author{
O. B. WILLIAMS, J. F. McCAFFREY, O. J. LAU
}

British Medical fournal, 1973, 1, 517-519

\section{Summary}

Investigation in the postoperative period of 75 patients by means of the radioiodinated fibrinogen uptake method, by the use of the Doppler ultrasonic flow detector, and by clinical assessment revealed an incidence of deep vein thrombosis of only $12 \%$. This is distinctly lower than has been reported by other investigators using the same techniques both in Australia and elsewhere. It appears from this study and associated work that the Doppler ultrasonic technique is sufficiently accurate to be of value in the clinical diagnosis of significant deep vein thrombosis.

\section{Introduction}

The Greenslopes Repatriation General Hospital in Queensland, Australia, provides medical services for ex-servicemen, mostly those who served in the first and second world wars. Because of the age of these patients and the fact that many of them suffer from chronic cardiac and respiratory diseases it was thought that many would develop deep vein thromboses after surgery.

\section{Methods and Subjects}

\section{RADIOIODINATED FIBRINOGEN UPTAKE}

Freeze-dried human fibrinogen tagged with ${ }^{125} \mathrm{I}$, prepared by the Radiochemical Centre, Amersham, England, was obtained from the Commonwealth Radiation Laboratory, Melbourne.

* Based on a paper presented at the 45th General Scientific Meeting of the Royal Australasian College of Surgeons.

\footnotetext{
University of Queensland Department of Surgery, Repatriation General Hospital, Queensland, Australia

O. B. WILLIAMS, M.B., P.R.C.s., Surgical Registrar

J. F. MCCAFFREY, M.B., F.R.C.S., Reader in Surgery

Department of Cardiothoracic Surgery, The London Hospital, London, E1 2AD

O. J. LAU, M.B., B.S., Registrar
}

This preparation was transported rapidly from England and the activity of the isotope was checked before its administration. It was usually possible to use each ampoule on or before the reference date at which the activity was 100 microcuries, thus ensuring that the isotope dose was sufficient to provide adequate counts during the period over which readings were taken. The fibrinogen was from donors with known donation records and was screened for Australian antigen. No degradation in the quality of the fibrinogen has been observed, and other groups in Australia are using the same product with equally satisfactory results. Before administering this material the thyroid gland was saturated with non-radioactive iodine by giving a sodium iodide mixture by mouth. A flavoured solution of $100 \mathrm{mg}$ sodium iodide per $10-\mathrm{ml}$ dose was acceptable to most patients, and this was continued for six weeks from the time of administration of the isotope.

A 100 microcurie dose (approximately) of the ${ }^{125} \mathrm{I}$ tagged fibrinogen was given intravenously on the day before operation, and measurements were performed at marked sites over both lower limbs preoperatively and on alternate days postoperatively for at least a week. A Pitman model 235 isotope localization monitor was used in this study. The legs of the patients were raised $10^{\circ}$ above the horizontal and measurements were taken over three sites on each thigh and five sites on each calf. Counts were measured as a percentage of the precordial count (this being taken as $100 \%$ ). A sustained rise of $20 \%$ or more was taken to indicate the development of a deep vein thrombosis at the site where the rise was noted. Details of this method of investigation have been previously described by Kakkar et al. (1970) and Flanc et al. (1968).

\section{DOPPLER ULTRASONIC FLOW DETECTOR}

Either a Parks Model 802 or Model 806 machine was used in this study. The output from the transmitting crystal is a narrow focused beam of $10 \mathrm{MHz}$ frequency and the probe is coupled to the skin using an acoustic coupling gel (Parker Aquasonic). The shift in the reflected signal is proportional to the velocity of blood flow in the vessel under study. The difference between the transmitted and received frequencies is amplified and is audible in high fidelity headphones. The Parks models have several advantages over other models used in similar studies because of the focused nature of the beam and the frequency used. The probe is applied over the femoral artery pulse and then moved 